\title{
Correction to: Well-Being and Territory: Methods and Strategies
}

\author{
Matteo Mazziotta ${ }^{1} \cdot$ Chiara Gigliarano $^{2} \cdot$ Stefania Rimoldi $^{3}$ \\ Published online: 9 February 2022 \\ (c) Springer Nature B.V. 2022
}

\section{Correction to: Social Indicators Research https://doi.org/10.1007/s11205-021-02645-3}

Unfortunately, the following articles were by mistake included in other issues but are part of the Special Issue on Well-Being and Territory: Methods and Strategies

"Tomaselli, V., Giuffrida, G., Gozzo, S. et al. Building Decision-making indicators Through Network Analysis of Big Data. Soc Indic Res 151, 33-49 (2020). https://doi.org/ 10.1007/s11205-020-02363-2

"Crocetta, C., Antonucci, L., Cataldo, R. eta al. Higher-Order PLS-PM Approach for Different Types of Constructs. Soc Indic Res 154, 725-754 (2021). https://doi.org/article/ 10.1007/s11205-020-02563-w

"Greco, F., Polli, A. Security Perception and People Well-being. Soc Indic Res 153, 741-758 (2021). https://doi.org/article/10.1007/s11205-020-02341-8

“Riniolo, V., Ortensi, L.E. Young Generations' Activism in Italy: Comparing Political Engagement and Participation of Native Youths and Youths from a Migrant Background. Soc Indic Res 153, 923-955 (2021). https://doi.org/article/10.1007/s11205-020-02487-5

An article note was included in the original version of the Editorial article stating the above information.

The original article has been corrected.

Publisher's Note Springer Nature remains neutral with regard to jurisdictional claims in published maps and institutional affiliations.

The original article can be found online at https://doi.org/10.1007/s11205-021-02645-3.

Matteo Mazziotta

mazziott@istat.it

Chiara Gigliarano

chiara.gigliarano@uninsubria.it

Stefania Rimoldi

stefania.rimoldi@unimib.it

1 Italian Institute of Statistics, Rome, Italy

2 University of Insubria, Varese, Italy

3 University of Milano - Bicocca, Milan, Italy 